\title{
A atuação do Ministério Público na implantação de Ecopontos do município de Salvador, Bahia, Brasil
}

The Public Prosecution Service Performance in a Recycling Center implementation in Salvador city, Bahia, Brazil

\author{
Cristina Maria Dacach Fernandez Marchi', Gleycielle Santos de Almeida"
}

\begin{abstract}
RESUMO
Os municípios enfrentam grandes desafios para a aplicação efetiva das exigências feitas pela Política Nacional dos Resíduos Sólidos, o que não os desobrigam a cumprir este instrumento legal. Este trabalho pretende examinar praticas de manejo e do descarte dos resíduos sólidos no município de Salvador, Bahia, e como estas podem gerar intervenções do Ministério Público. Trata-se de estudo exploratório, descritivo e analítico. Foi possível observar que a atuação do Ministério Público do Estado da Bahia vem sendo relevante para a efetivação do preconizado pela Lei. Sem a participação deste órgão, descrita neste estudo, a cidade do Salvador poderia não estar contando com o único e adequado equipamento público para a coleta de recicláveis, como o Ecoponto do Itaigara, oriundo de um Termo de Ajuste de Conduta.
\end{abstract}

Palavras-chave: Ações Municipais; Termo de Ajuste de Conduta; Política Nacional dos Resíduos Sólidos; Gestão de Resíduos Sólidos

\section{ABSTRACT}

The Brazilians municipalities face great challenges in promoting effective application of minimum legal requirements for the management of solid waste. This paper aims examine the practices and challenges of management and disposal solid waste in Salvador city, Bahia, Brazil, and how these are expected to generate significant public interest in order to report to the Public Prosecution Service in the city of Salvador, Bahia. It is an exploratory and descriptive study. It was possible to observe the performance of the Public Prosecution Service. They have been a Political and Institutional influence on effectiveness in the Solid Waste Policy. Without their participation, on the case described in this study, the city of Salvador could not have the only and adequate public equipment to recyclables collection, such as the Itaigara's recycling center, originated from a Conduct Adjustment Agreement

Keywords: Municipalities Actions; Conduct Adjustment Agreement; Brazilian Policy on Solid Waste

\section{INTRODUÇÃO}

A Lei 12.305/2010 instituiu a Política Nacional dos Resíduos Sólidos (PNRS) no intuito de regulamentar a responsabilidade dos entes federativos da União (Estados, Municípios e Distrito Federal) relativa à geração de resíduos sólidos urbanos - RSU em seu território. Este marco determina que cada ente elabore planejamento próprio ou integrado para o gerenciamento. O Artigo $1^{\circ} \mathrm{da}$ PNRS dispóe sobre Princípios, Objetivos e Instrumentos, bem como sobre as Diretrizes relativas à gestão integrada e ao gerenciamento de resíduos sólidos, às Responsabilidades dos geradores e do poder público e aos Instrumentos aplicáveis. Estáo sujeitas à observância desta Lei as pessoas físicas ou jurídicas, de direito público ou privado, responsáveis, direta ou indiretamente, pela geração de resíduos sólidos. A Lei 12.305/2010 estabelece que a elaboraçáo dos planos é condição necessária para que o Distrito Federal e municípios tenham acesso à recursos da União, ou recursos que por ela sejam controlados, destinados a empreendimentos e serviços relacionados à limpeza urbana e ao manejo de resíduos sólidos, ou ainda para serem

\footnotetext{
' Programa de Pós Graduação em Planejamento Ambiental da Universidade Católica do Salvador. cristina.marchi@pro.ucsal.br

"Administradora, Integrante do Grupo de Pesquisa em Gestão Ambiental e Desenvolvimento de Empreendimentos Sociais - GAMDES da UCSAL Universidade Católica do Salvador. gleycielle I7@hotmail.com
} 
beneficiados por incentivos ou financiamento de entidades federais de crédito ou de fomento para tal finalidade (BRASIL, 2010).

A responsabilidade dos cidadãos aponta para a direção de participação integrada no ciclo de vida dos produtos, conjuntamente com as organizaçóes públicas e privadas. A atuaçáo da sociedade é de fundamental importância, já que existe a necessidade de redução da geração dos resíduos domésticos e do descarte apropriado nos equipamentos de coleta seletiva, disponibilizados pelos gestores públicos.

Alguns equipamentos públicos, disponibilizados pelas prefeituras, se manejados corretamente, são fundamentais para a coleta seletiva. Como exemplos, podem-se citar contêineres de Pontos de Entrega Voluntária - PEV, Ecopontos, carrinhos elétricos disponibilizados para cooperativas de catadores de material reciclável, caminhóes com chassi multi coleta, Unidades de Transbordo, Usinas de Triagem e de Reciclagem, Área de Transbordo e Triagem de Resíduos da Construção - RCC e volumosos (ATT) e Aterros Sanitários.

Desse modo, pela ótica da PNRS, agentes públicos estimulam com as suas açôes a participação ativa dos cidadãos e das empresas para o adequado descarte. Entretanto, este estímulo, principalmente na região Nordeste, ainda é incipiente, os municípios ainda se encontram despreparados para esta importante tarefa.

As informaçōes sobre a gestão municipal dos resíduos sólidos no território brasileiro apontam para um quadro preocupante. O Sistema de Informaçóes sobre Resíduos Sólidos - SNIS (2016), com ano base no ano de 2015, é um estudo divulgado pelo Ministério das Cidades. Prestaram informaçóes para este estudo 3.520 do total de 5.570 municípios brasileiros $(63,2 \%)$. Os resultados sobre a destinação final correta apontam para somente 679 municípios possuírem aterros sanitários, a maioria localizada nas regióes Sul e Sudeste (81,6\%). A regiáo Nordeste possui quase $58 \%$ do total de 1.140 "lixóes" espalhados pelo território nacional, ou seja, 661 unidades. Do total de participantes da amostra do SNIS, somente 1.256 afirmam possuir coleta seletiva (SNIS, 2016).

Quanto ao exercício do direito à coleta seletiva, nada pode ser mais inútil do que as ações de um cidadão consciente, que pratica todas as etapas corretas para a segregação, o acondicionamento e o descarte dos seus resíduos em pontos de coleta seletiva, quando postas em confronto com o péssimo manejo público, que coleta e mistura todos os resíduos encontrados sem nenhum cuidado, ou ainda, com a atitude de pessoas desatentas, que jogam resíduos orgânicos em caixas coletoras, destinadas unicamente para o descarte de material reciclável, contribuindo para a poluição do meio ambiente.

A maneira que o material é descartado é um passo fundamental para amenizar os problemas ambientais. $\mathrm{Na}$ Alemanha, o governo considera que os resíduos sólidos se constituem em recursos. Orienta suas políticas públicas de produção em direçáo ao fechamento de ciclos, ou seja, os resíduos sáo transformados em insumos para novos processos de produção de bens. Esses ciclos são alimentados por praticas cidadãs.

No Brasil, as práticas corretas são claramente determinadas pela Lei 12305/2010. O Ministério Público atua na fiscalização, para a normatização ser observada por agentes públicos, pelas empresas e pela sociedade.

Este trabalho, de caráter exploratório, pretende examinar algumas praticas do processo de manejo dos resíduos sólidos, tais como o descarte, a coleta seletiva e a destinação final, gerados por empresas e pelos cidadãos no município de Salvador, Bahia, e como essas praticas podem suscitar intervençôes do Ministério Público.

\section{NORMAS RELACIONADAS AOS RESÍDUOS SÓLIDOS NO BRASIL}

De acordo com a Norma Técnica - NBR 10.004 da Associação Brasileira de Normas Técnicas, de 2004, os resíduos sólidos são definidos como:

Resíduos nos estados sólido e semissólido, que resultam de atividades de origem industrial, doméstica, hospitalar, comercial, agrícola, de serviços e de varrição. Ficam incluídos nesta definição os lodos provenientes de sistemas de tratamento de água, aqueles gerados em equipamentos e instalaçôes de controle de poluição, bem como determinados líquidos cujas particularidades tornem inviável o seu lançamento na rede pública de esgotos ou corpos de água ou exijam para isso soluçôes técnica e economicamente inviáveis em face à melhor tecnologia disponível (NBR 10004, p.1).

A NBR 10.004 adverte que esses tipos de resíduos sólidos podem causar risco à saúde pública, provocando mortalidade, incidência de doenças ou acentuando seus índices; e riscos ao meio ambiente, quando o resíduo for gerenciado de forma inadequada. Portanto, o gerenciamento adequado dos resíduos sólidos tem relação direta com a mitigação de impactos ambientais, ou seja, o gerenciamento pode minimizar os impactos ambientais nocivos, causados pelos RSU. 
Quadro 1.0 - Normas que embasam Planos de Gerenciamento Integrado de Resíduos Sólidos

\begin{tabular}{|c|c|c|}
\hline Normas & Proposiçōes & Pontos Relevantes para o Meio Ambiente \\
\hline Lei Federal n 6.766/1979 & $\begin{array}{l}\text { Define as competências do Estado e do } \\
\text { Município sobre a questáo do parcelamento } \\
\text { do solo. }\end{array}$ & $\begin{array}{l}\text { Interface de áreas contaminadas com o } \\
\text { desenvolvimento urbano. Não permite o } \\
\text { parcelamento do solo em áreas poluídas, em } \\
\text { terrenos que tenham sido aterrados com } \\
\text { material nocivo à saúde pública, sem que } \\
\text { sejam previamente saneados. }\end{array}$ \\
\hline Lei Federal nº 6.938/1981 & $\begin{array}{l}\text { Regulamentada pelo Decreto no } 99.274 / 1990 \text {, } \\
\text { define a Política Nacional do Meio Ambiente. }\end{array}$ & $\begin{array}{l}\text { Regula a estrutura administrativa de proteção } \\
\text { e de planejamento ambiental, o Sistema } \\
\text { Nacional do Meio Ambiente (SISNAMA). }\end{array}$ \\
\hline Constituição Federal do Brasil de 1988 & $\begin{array}{c}\text { Assegura o exercício dos direitos sociais e } \\
\text { individuais, a liberdade, a segurança, o bem } \\
\text { estar, o desenvolvimento, a igualdade e a } \\
\text { justiça. }\end{array}$ & $\begin{array}{l}\text { Capítulo VI ("Do Meio Ambiente"), Artigo } \\
\text { 225, é colocado, dentre outros, o princípio } \\
\text { que todos têm direito ao meio ambiente } \\
\text { ecologicamente equilibrado }\end{array}$ \\
\hline $\begin{array}{l}\text { Resolução CONAMA n. }{ }^{\circ} 005 \text {, de } 31 \text { de } \\
\text { março de } 1993\end{array}$ & $\begin{array}{l}\text { Dispóe sobre o tratamento de resíduos } \\
\text { sólidos gerados em estabelecimentos de saúde, } \\
\text { portos e aeroportos e terminais ferroviários e } \\
\text { rodoviários. }\end{array}$ & $\begin{array}{l}\text { Considera que a qualidade do meio ambiente } \\
\text { e as açóes preventivas sáo menos onerosas } \\
\text { e minimizam os danos à saúde pública e ao } \\
\text { meio ambiente. }\end{array}$ \\
\hline Lei ordinária n. ${ }^{\circ}$ 787, de 1997 & $\begin{array}{l}\text { Dispóe sobre o Programa de Prevençáo de } \\
\text { Contaminaçáo por Resíduos Tóxicos, a ser } \\
\text { promovido por empresas fabricantes de } \\
\text { lâmpadas fluorescentes, de vapor de mercúrio, } \\
\text { vapor de sódio e luz mista }\end{array}$ & $\begin{array}{l}\text { As empresas fabricantes devem promover, em } \\
\text { associação e com o apoio do Poder Público, } \\
\text { programas permanentes de prevençãa } \\
\text { de contaminaçáo por resíduos tóxicos } \\
\text { provenientes dos seus produtos. }\end{array}$ \\
\hline $\begin{array}{c}\text { Resoluçāo CONAMA n. }{ }^{\circ} \text { 237, de } 19 \text { de } \\
\text { dezembro de } 1997\end{array}$ & $\begin{array}{l}\text { Estabelece norma geral sobre licenciamento } \\
\text { ambiental, competências, listas de atividades } \\
\text { sujeitas a licenciamento }\end{array}$ & $\begin{array}{l}\text { Define Licenciamento Ambiental; Licença } \\
\text { Ambiental; } \\
\text { Estudos Ambientais e Impacto Ambiental } \\
\text { Regional. }\end{array}$ \\
\hline Lei no 9.605/98 & $\begin{array}{c}\text { Sobre as sançóes penais e administrativas } \\
\text { derivadas de lei de crimes ambientais, } \\
\text { condutas e atividade lesivas ao meio } \\
\text { ambiente. }\end{array}$ & Prevê penas de reclusão de até cinco anos \\
\hline Lei no. $11.445 / 2007$ & $\begin{array}{c}\text { Estabelece as diretrizes nacionais para o } \\
\text { saneamento básico e a política federal de } \\
\text { saneamento básico }\end{array}$ & $\begin{array}{l}\text { Estabelece a responsabilidade do titular dos } \\
\text { serviços públicos de saneamento básico. }\end{array}$ \\
\hline Decreto n. ${ }^{\circ} 7.217 / 2010$ & Regulamenta a Lei n. ${ }^{\circ} 11.445 / 2007$ & $\begin{array}{l}\text { Estabelece normas para a execuçáo das } \\
\text { diretrizes nacionais para o saneamento básico. }\end{array}$ \\
\hline Lei no 12.305 , de 2 de agosto de 2010 & $\begin{array}{l}\text { Institui a Política Nacional de Resíduos } \\
\text { Sólidos - PNRS; altera a Lei n. }{ }^{\circ} 9.605 \text {, de } 12 \\
\text { de fevereiro de 1998; e dá outras providências }\end{array}$ & $\begin{array}{l}\text { Considera área contaminada o local onde } \\
\text { há contaminaçáo causada pela disposiçáo, } \\
\text { regular ou irregular de quaisquer substâncias } \\
\text { ou resíduos. }\end{array}$ \\
\hline Decreto n. ${ }^{\circ} 7.404 / 2010$ & Regulamenta a Lei n. ${ }^{\circ} 12.305 / 2010$ & $\begin{array}{c}\text { Estabelece normas para a execução da Política } \\
\text { Nacional de Resíduos Sólidos }\end{array}$ \\
\hline
\end{tabular}

Fonte: Elaboração das autoras

Para Marchi (2015) o Gerenciamento Integrado de Resíduos Sólidos é a coparticipação no sistema de manejo da limpeza urbana (acondicionamento, coleta, triagem e reciclagem, transporte, tratamento e destinação final dos rejeitos). Envolve diferentes órgãos da Administração Pública, das organizações privadas e da sociedade civil, objetivando elevar a qualidade de vida da população e promover o desenvolvimento sustentável.

Um instrumento que apoia o gerenciamento integrado de resíduos sólidos é o Plano de Gerenciamento Integrado de Resíduos Sólidos (PGIRS), documento que diagnostica a situação atual e traça cenários para o sistema de limpeza urbana. O plano de gerenciamento integrado estabelece diretrizes e açôes ligadas aos aspectos 
ambientais, econômicos, financeiros, administrativos, técnicos, sociais e legais, desde a geração até a destinação final dos resíduos sólidos.

As ações normativas, operacionais, financeiras e de planejamento, que compóem o plano de gerenciamento integrado dos resíduos sólidos, devem se processar de modo articulado, porque as atividades e procedimentos envolvidos nesse componente do saneamento básico encontram-se interligados, comprometidos entre si.

A interligaçáo entre as diferentes esferas necessita de instrumentos legais que a fundamentem. Desde os anos oitenta, as legislaçôes federais (Quadro 1.0) que vêm atuando como ferramenta de apoio na inter-relação entre resíduos sólidos, sociedade e meio ambiente.

Merece destaque a promulgação da PNRS, a Lei 12.305/2010, que é instrumento primordial para resolver demandas de atos processuais no manejo dos resíduos sólidos, tratando questóes sobre geração, reutilização e geração de renda, a partir de insumos derivados de materiais recicláveis, até sobre rejeitos, quando já não há nenhum tipo de utilidade ou maneira de aproveitá-los, seguindo para a destinação final adequada. Logo, este marco regulatório define diretrizes importantes para nortear as ações necessárias para a gestão dos resíduos sólidos em todas as esferas: federal, estadual e municipal.

A PNRS traz em seu escopo definiçốes importantes como a da gestão integrada e responsabilidade compartilhada pelo ciclo de vida dos produtos, deixando, de certa forma, definidas as responsabilidades dos agentes sociais - Governo, empresas privadas e sociedade civil - para o melhor gerenciamento dos resíduos. Incluindo assim, os fabricantes, importadores, distribuidores e comerciantes, os consumidores e os titulares dos serviços públicos de limpeza urbana. Oferece para tanto, instrumentos de gestáo que devem ser elaborados pelos agentes públicos e governamentais com a participação ativa da sociedade civil, dentre eles: os planos de gestão de resíduos sólidos e os planos de gestáo integrada de resíduos sólidos, que devem prever a parcela de responsabilidade de cada um desses agentes.

O princípio do poluidor-pagador consta no inciso II do Cap. 6 da PNRS. Entretanto, já se fazia presente na Constituição de 1988. Porém, de forma explicita, a Lei 12305/2010 adota este princípio visando garantir um meio ambiente equilibrado e punir economicamente aquele que $\mathrm{o}$ agride.

O conjunto de Normas, acima destacadas, conjuntamente com outras, apoia as práticas cotidianas da sociedade brasileira relacionadas ao manejo dos RSU. Cabe também aos agentes do Ministério Publico atuar na defesa desta ordem jurídica e dos interesses e direitos sociais e individuais.

\section{METODOLOGIA}

Trata-se de um estudo exploratório, que teve como finalidade identificar algumas praticas no manejo (segregação, coleta e destinação final) dos resíduos sólidos gerados por empresas e pelos cidadãos, no município de Salvador, Bahia, e como algumas podem suscitar intervenções do Ministério Público.

O delineamento utilizado foi a pesquisa bibliográfica, que empregou fontes secundárias, artigos, textos científicos e livros ligados ao tema. A busca bibliográfica virtual foi desenvolvida por meio de informaçóes em bibliotecas inseridas no portal da Scientific Eletronic Library Online (SCIELO), Pubmed e base de dados: Elsevier SciVerse ScienceDirect, SciVerse Scopus. Essa busca procedeu-se desde maio de 2017 a dezembro de 2018, utilizando os seguintes descritores: coleta seletiva e destinação resíduos sólidos, alternativas tecnológicas para coleta seletiva, Termo de Ajuste de Conduta em RSU.

Para evidenciar e ilustrar a relação dos aspectos de manejo inadequado e a intervenção do Ministério Público foi descrito um estudo de caso que relata a instalação de um Ecoponto, no bairro do Itaigara, Salvador, por meio da aplicação pelo Ministério Público de um Termo de Ajuste de Conduta (TAC) especifico, merecedor de destaque pelo seu caráter educativo.

Definido o núcleo de interesse dos pesquisadores, foi aplicada uma entrevista semiestruturada, com perguntas abertas e com aplicação flexível das questóes, já que se buscava adequar o roteiro proposto ao universo de atuação da Responsável pela 5ª Promotoria de Justiça de Meio Ambiente do Ministério Público da Bahia.

Quanto aos procedimentos sistemáticos para a descrição e explicação dos resultados gerados, o estudo preconizou a abordagem qualitativa, pois os mesmos foram analisados de forma crítica, balizados pelos instrumentos legais contidos na PNRS, a Lei 12.305/2010, pela observação do gerenciamento do Ecoponto e a sua contribuição para minimizar os danos que comprometem o meio ambiente urbano causados pelo desconhecimento da reduçáo, do reuso e da reciclagem. Finalmente, com as análise realizadas foi desenvolvido um quadro analítico sobre a relação entre os Princípios da PNRS e o TAC do Ecoponto Itaigara. 


\section{RESULTADOS ENCONTRADOS}

\section{I Equipamentos relativos à Disposição dos Resíduos Sólidos em Salvador}

A partir da promulgação da PNRS, os municípios brasileiros têm se deparado com inúmeros desafios que corroboram para o retardo no atendimento dos serviços de resíduos sólidos. Dentre eles é possível citar a complexidade e interconexôes da variável ambiental com outros problemas, sociais, econômicos, espaciais e culturais. Além de outros como descontinuidade política, e falta de mão de obra técnica e qualificada para a elaboração, acompanhamento e avaliaçáo dos programas que tenham origem nos planos de gestáo de resíduos (FERNANDES ET al, 2012).

Programas que minimizem danos que o descarte inadequado que resíduos sólidos promovem no meio ambiente podem ser descritos. Exemplos educativos acontecem na Europa. Mannarino et al. (2016) apresentam dados sobre gestão, coleta e tecnologias europeias para tratamento e disposição final de RSU. Descrevem que a Suíça cobra altas tarifas na coleta "... cada saco de 35 L custa entre 2 e 3 Francos Suíços (SFr) [...] incentiva à população a separar os resíduos recicláveis e tratáveis biologicamente, a fim de reduzir os gastos para o recolhimento dos resíduos gerados" (MANNARINO et al., 2016, p.3)

As estatísticas sobre as etapas de manejo dos RSU ajudam a entender o gerenciamento dos resíduos nos países. O estudo de Conke \& Nascimento (2018) explica as diferenças estatísticas sobre os dados sobre coleta seletiva no Brasil por meio da comparação dos procedimentos metodológicos adotados nas pesquisas brasileiras. Os autores apresentam percentuais divergentes dos relatórios municipais que oferecem a coleta seletiva que, segundo os autores, variam de $14 \%, 20 \%, 32 \%$ ou até $60 \%$. Sem dados confiáveis os gestores não podem encontrar caminhos que o orientem para a gestão adequada. Ribeiro et al (2014) apontam a reciclagem de resíduos como uma medida econômica, social e ambientalmente viável para se tentar reverter o quadro de impactos ambientais que os RSU causam ao meio ambiente. A coleta seletiva pressupóe a reciclagem. Os autores exemplificam latas de alumínio como resíduos que vêm sendo progressivamente reciclados,

A redução de lixo na fonte de geraçáo associa-se tanto a mudanças tecnológicas nos produtos e nos processos produtivos quanto a modificaçôes no padrão de consumo da população, sejam tais mudanças induzidas por políticas públicas ou não. Um exemplo é o aumento de $47 \%$ na produtividade da reciclagem das latas de alumínio desde 1968; nesse ano, eram produzidas 42 latas de $350 \mathrm{ml}$ com um quilo de alumínio reciclado, e atualmente são produzidas 62 latas. (RIBEIRO et al, 2014, p.195).

Apesar de todos os desafios encontrados, sobretudo na gestão municipal, é possível encontrar no município de Salvador algumas iniciativas voltadas para o aprimoramento desses serviços, tais como: instalação de Pontos de Entrega Voluntária - PEV e outros instrumentos voltados para a coleta seletiva.

No Brasil, equipamentos conhecidos como PEV servem como depósito de resíduos sólidos não perigosos domésticos ou comerciais onde são recebidos materiais recicláveis (papel, metal, plástico e vidro). Neste município também foi encontrado um Ecoponto.

Ecoponto é um equipamento público que deve ser instalado em locais de fácil acesso para entrega voluntária de resíduos sólidos urbanos (RSU) recicláveis, bem como, resíduos da construção civil, além de outros, de pequeno volume, que não são classificados como domésticos tais como: pequenos volumes de restos de materiais de construção; pilhas e baterias; pneus; moveis e eletrodomésticos. Estes locais são voltados para o recebimento de resíduos sólidos não perigosos, domésticos, comerciais e industriais, que podem ou não ser destinados à reciclagem. Ecopontos recebem, geralmente, resíduos que a sociedade não sabe onde descartar. Resíduos que por não serem recolhidos pela coleta realizada pela limpeza urbana municipal, acabam nos logradouros, nas vias públicas, causando danos à saúde da população e dando origem aos lixôes clandestinos.

No intuito de realizar algumas ações para minimizar o despejo irregular, a Secretaria Cidade Sustentável do município de Salvador - SECIS criou um aplicativo com o qual o cidadáo pode localizar o equipamento mais próximo para o descarte apropriado de seus resíduos. Como mostra o Mapa a seguir. 
Mapa dos Pontos de Entrega Voluntária do município de Salvador (2017)

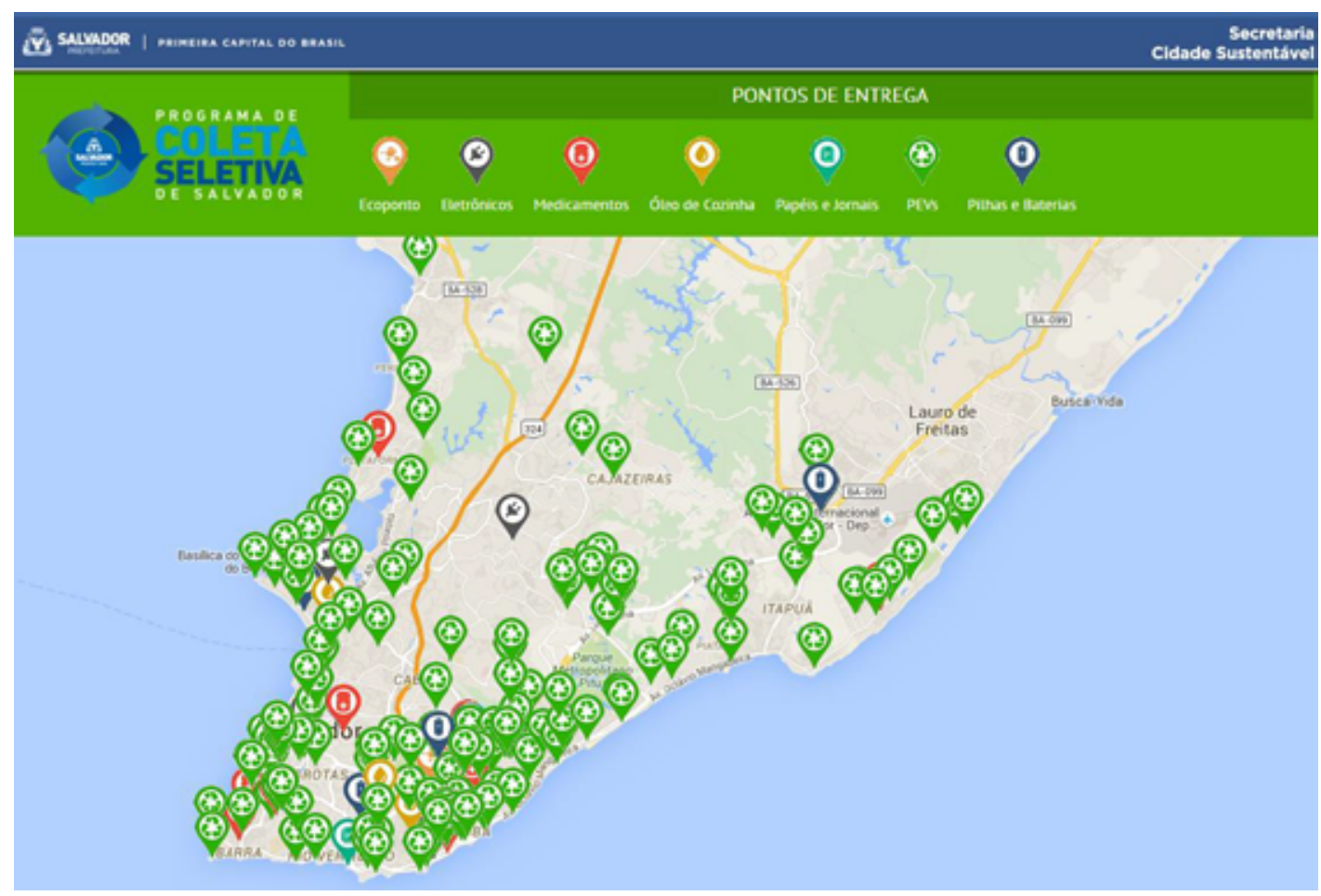

Fonte: http://www.coletaseletiva.salvador.ba.gov.br/

Klein et al (2018) realizaram estudo visando analisar de que forma tecnologias de informação e comunicação (TIC) e a internet apoiam a gestão de resíduos no município de São Paulo. Os autores afirmam que a maioria dos 34 municípios da Bacia Hidrográfica do Alto Tietê subutilizam os TIC e não promovem, adequadamente por meio destes, a difusão de informaçôes importantes para a população sobre açôes relevantes relacionadas à separaçáo e ao acondicionamento dos resíduos sólidos para a coleta seletiva. Os autores concluem que um melhor uso desses recursos podem apoiar o cumprimento dos objetivos e metas determinados pela PNRS.

Cabe a observação de que a simples disponibilização desses pontos de descarte em aplicativo, não se torna suficiente para o atendimento apropriado do volume de RSU gerado no município de Salvador. Apesar do dispositivo ser elemento importante na questão do descarte adequado, a disponibilizaçâo desses pontos está concentrada na parte litorânea do município, enquanto bairros mais afastados e bastante povoados, como o bairro de Aguas Claras no subúrbio, vêm recebendo poucos equipamentos dessa categoria.

Chama a atenção, no bairro de Aguas Claras e em outros bairros afastados, que ainda não exista um sistema de coleta seletiva; nem o do tipo porta a porta. A distribuição desproporcional entre número de PEV que foram instalados neste bairro e a sua população exige grande esforço daqueles que desejam descartar corretamente seus resíduos.

Para o efetivo atendimento, além da disponibilização de um aplicativo para localizar PEV disponível, faz-se necessária a instalação de uma maior quantidade destes equipamentos nos bairros mais afastados do Centro. A população que vive na periferia tende a descartar de maneira inapropriada os resíduos e/ou rejeitos, até por falta de informação e de fiscalização adequadas. Outra dificuldade sentida é o desenvolvimento de campanhas orientadas para as questóes do descarte inadequado e suas consequências, além de chamar a atenção para o correto manejo de cada tipo de material, aqueles que têm potencial para serem reutilizados.

Apesar de contribuírem positivamente para a destinação final do RSU, o PEV não atende apropriadamente a destinação dos resíduos sólidos não domésticos, como por exemplo o Resíduo da Construção Civil (RCC) de pequenos produtores, advindos de pequenas reformas ou construçóes, responsáveis por aproximadamente $70 \%$ do descarte dos RSU no Brasil (MARCHI, 2015).

Para este tipo de resíduo o mais recomendado e apropriado seria o Ecoponto, que possui estrutura necessária para sua disposição, mesmo não se caracterizando como equipamento para disposição final de RCC, que seria o aterro de inertes. 
Entretanto, até setembro de 2017, a cidade de Salvador contava com apenas um Ecoponto com estrutura apropriada em funcionamento, voltado para recebimento de materiais que não podem ser descartados conjuntamente com os recicláveis, por exemplo: sofá, cadeiras, armários, tintas, pneus, eletrodomésticos, etc.

As Fotos 1.0 e 2.0 mostram o Ecoponto, instalado à Rua Wanderley Pinho, bairro do Itaigara. Ao contrário do que acredita o senso comum, a sua construção não foi uma iniciativa do poder municipal, mas sim da atuação do Ministério Público da Bahia (MP/BA) através de um Termo de Ajustamento de Conduta - TAC, um dos instrumentos mais usados pelo MP/BA para acordos com potenciais poluidores, abrangendo inclusive agentes da gestão municipal. Este TAC em questão foi firmado por três empreiteiras do ramo da construção civil que depositavam entulho em local inapropriado, sendo aplicado neste contexto um dos princípios da PNRS de 2010, o princípio do poluidor-pagador.

Fotos 1.0 e 2.0 - Ecoponto instalado no Bairro do Itaigara - Salvador
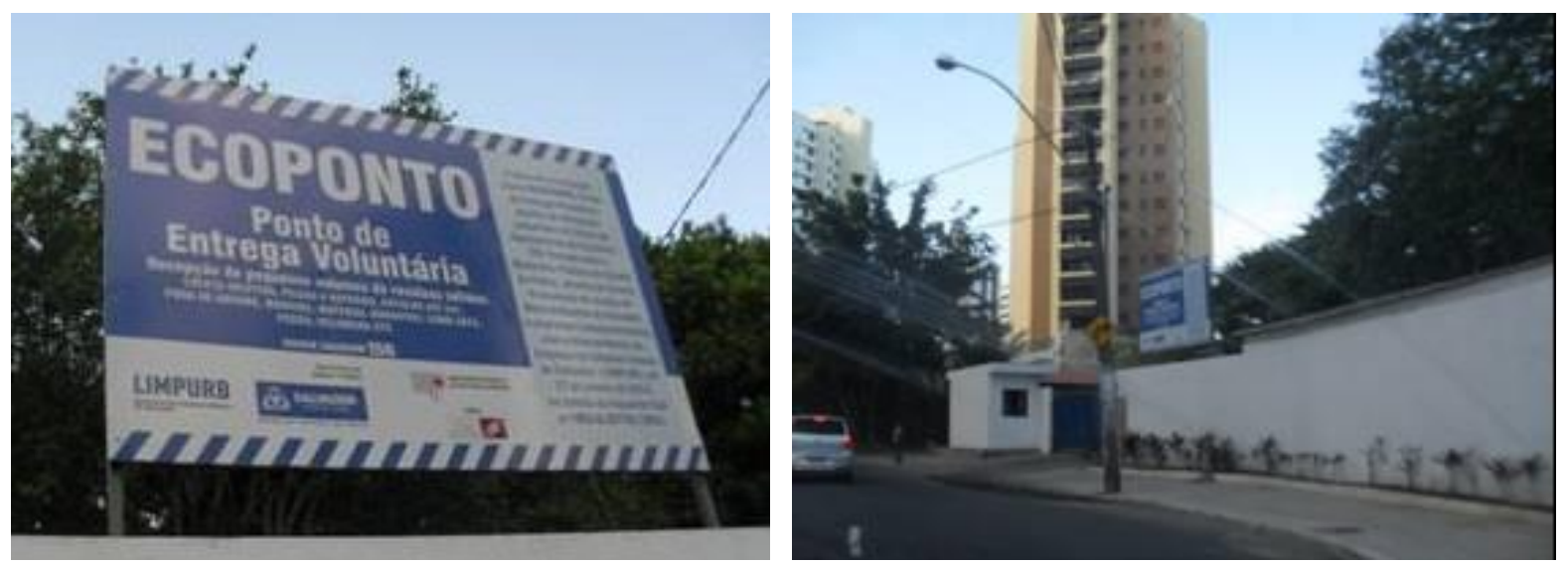

Fonte: Autoras (2016)

\subsection{Ações do Ministério Público da Bahia}

O Ministério Público brasileiro é uma instituição permanente, a qual lhe é incumbida a defesa da ordem jurídica, do regime democrático no país e dos interesses sociais e individuais indisponíveis. Dentre os seus órgãos de execuçáo encontra-se os Procuradores de Justiça e Promotores de justiça que atuam em nome do Ministério Público estadual (BRASIL, 1993).

Os interesses sociais e individuais indisponíveis são aqueles aos quais não se pode renunciar, como: a vida, a liberdade, a educação e a saúde. Além disso, o Ministério Público fiscaliza o cumprimento das leis, podendo acionar o poder judiciário. Para aprofundamento deste trabalho, o Ministério Público da Bahia foi procurado para esclarecer como vem atuando no setor dos resíduos sólidos urbanos. Buscou-se também saber quais as principais açóes da 5a Promotoria de Justiça de Meio Ambiente (5a PJMA), nos últimos anos, no apoio ao que determina a Lei 12.305/2010. Em Entrevista com a promotora de justiça responsável pela 5a PJMA foi possível obter informaçóes sobre esse tema e de que forma isso vem acontecendo.

Vale salientar que, no Brasil, a presença do Ministério Público junto ao manejo de resíduos sólidos já vem acontecendo há alguns anos. Lima (2018) relata que o termo de ajustamento de conduta (TAC) assinado em 2011 entre a Refinaria Duque de Caxias da Petrobras, a Secretaria de Estado do Ambiente (SEA) Rio de Janeiro e o Instituto Estadual do Ambiente (Inea) determinou que a Petrobrás investisse R \$ 3,5 milhóes para a instalação do polo de reciclagem de Jardim Gramacho, Rio de Janeiro.

A PNRS, dentre suas determinaçôes, prevê instrumentos legais dos quais o poder público pode se valer para garantir o exigido em seu escopo. Em seu Art. $8^{\circ}$, incisos XVIII e XIX ela descreve os termos de compromisso, os TAC e o incentivo à adoção de consórcios ou de outras formas de cooperação entre os entes federados, com vistas à elevação das escalas de aproveitamento e à reduçáo dos custos de envolvidos, como instrumentos da PNRS.

Além do TAC, outros dois instrumentos utilizados são a ação civil pública e o inquérito civil que ocorrem quando o poluidor não aceita o TAC ou não cumpre suas determinaçôes. Apesar do TAC não ser o único, foi apontado como o principal e dos mais importantes instrumentos utilizados pelo MP para lidar com danos de pequenas proporções causados ao meio ambiente. Atualmente, tem ensejado a construção de Ecopontos 
no município. É ainda um dos que tem mostrado mais eficácia para a reparação do impacto causado ao meio ambiente, após os danos já causados e sendo eles reversíveis, pois é um instrumento mais célere se comparado aos outros disponíveis para este fim.

No TAC do Ecoponto do Itaigara, os signatários se responsabilizaram pela construção da estrutura física do equipamento, em terreno cedido pelo poder público, e gerenciado pela Empresa de Limpeza Urbana de Salvador - LIMPURB. Os agentes poluidores, que foram convidados a celebrarem este acordo com o Ministério Público como forma de reparação aos danos causados ao meio ambiente pelo descarte inadequado de Resíduos da Construção Civil (RCC), responsabilizaram-se ainda pela impressão de determinada quantidade de cartilhas e panfletos, inseridas orientações básicas sobre quantidades e tipos de resíduos a serem entregues no Ecoponto. Ferreira et al. (2014) apontam a Resolução Conama No 358/2005 e a RDC 306/2004, como instrumentos que promovem um melhor gerenciamento dos RCC. Os autores afirmam que estas normas indicam os tipos de RCC e a destinação apropriada. Chamam a atenção para a responsabilidade dos geradores para cumprirem adequadamente as etapas de manejo e que não cabe "... à prefeitura realizar coleta e nem arcar com a destinação final em órgãos privados" (FERREIRA et al., 2014, p.3406).

Quando questionada se não seria melhor indicar aos agentes poluidores outro tipo de divulgação, que impactasse ou chamasse mais a atenção do cidadáo por meios massivos de comunicação, a entrevistada apontou que no caso em questão foi sugerido o processo comunicativo por meio de impressos. A sugestáo se deu porque os materiais utilizados neste processo possuem custos menores. Os agentes poluidores em questão não foram empresas de grande porte e, sim, pequenos empresários ou empreiteiros. Esta decisão foi tomada observando equilíbrio financeiro, já que o porte econômico dos envolvidos não comportaria altos custos com comunicação. Entretanto, concordou que este tipo de material educativo é insuficiente para atingir um número significativo da população.

Através do TAC é possível observar a atuação conjunta de vários setores da sociedade: a participação dos agentes poluidores, que neste caso eram empresas privadas; a participação do poder público: a prefeitura, quando o município de Salvador cede local apropriado; além da participação da empresa responsável pela limpeza urbana do município, administrando o local escolhido.

A parceria também poderia ser realizada por meio de parcerias firmadas entre a Administração Pública e as organizaçóes da sociedade civil, como as cooperativas de materiais recicláveis. O disposto na Lei Federal $\mathrm{n}^{\mathrm{o}} 13.019$, de 2014, permite este arranjo, que pode construir uma via criativa e promissora para a resoluçáo de problemas sociais e institucionais dos trabalhadores dessas cooperativas.

A partir da situação apresentada, pode se notar práticas dispostas na PNRS, tais como: inciso VI, art. $6^{\circ}$ da PNRS, que dispóe sobre o princípio da cooperaçấo entre as diferentes esferas do poder público, o setor empresarial e demais segmentos da sociedade; o inciso VIII, art. $7^{\circ}$, que trata do reconhecimento do resíduo sólido reutilizável e reciclável como um bem econômico e de valor social, gerador de trabalho e renda e promotor de cidadania. Fica também atendido um importante objetivo da lei $12.305 / 2010$, listado ao inciso VI, art. $7^{\circ}$ : gestão integrada dos resíduos sólidos. Bem como, o princípio do poluidor-pagador.

Pelo contexto descrito acima, tornam-se mais claras as ações realizadas pelo MP/BA para a disposição do que é exigido e objetivado pela PNRS. Apesar da construçáo dos Ecopontos não serem de responsabilidade do MP, pois a responsabilidade é do gestor municipal, também por iniciativa do Ministério Público da Bahia, através de TAC firmado entre os poluidores e a 5a PJMA, outros dois projetos ligados ao Ecoponto estáo sendo planejados pelo município de Salvador, nos bairros de Curralinhos e do Vale da Muriçoca.

A motivação para a ação do MP/BA junto aos RSU, por meio da proposição de assinatura deste instrumento, é a preocupação com os danos ambientais dos agentes poluidores, sejam eles pessoas físicas, jurídicas e até mesmo entes governamentais, como prefeituras.

Apesar de o TAC ter se mostrado bastante eficaz para que danos de menores proporções e reversíveis possam ser rapidamente sanados e apresentar um retorno mais imediato à sociedade, não se pode esquecer que este funciona apenas como um instrumento para lidar com as consequências da inobservância das leis pelos agentes sociais. Desta forma, o ideal é que o primeiro princípio da PNRS seja atendido, o princípio da prevenção e precaução.

Logo, todos os setores da sociedade devem estar comprometidos com o disposto na Lei 12.305/2010, desde o produtor/fabricante até o consumidor final, incluindo os gestores públicos através da disponibilização dos equipamentos e açóes necessárias, para acesso da populaçáo ao meio correto de descarte.

De acordo com informaçóes obtidas em entrevista com a promotora de justiça da $5^{\text {a }}$ PJMA, foi possível elaborar um quadro comparativo descrevendo quais Princípios (art. $6^{\circ}$ ) da PNRS são atingidos com a disposição desses equipamentos públicos de coleta e entrega voluntária de resíduos e as repercussões da ação praticada pelo MP, por meio da TAC apresentado no Quadro 2.0. 
Quadro 2.0: Análise da Relação entre os Princípios da PNRS e o Termo de Ajuste de Conduta - Ecoponto Itaigara

\begin{tabular}{c|c}
\hline Princípios da PNRS & Análise da Relação: TAC \\
\hline I - a prevenção e a precaução; & $\begin{array}{c}\text { Apesar da atuação do MP ter ocorrido após o incidente e o agravo ocorridos, } \\
\text { este princípio adverte aos novos e futuros poluidores para as penalidades. }\end{array}$ \\
\hline II - o poluidor-pagador e o protetor-recebedor; & $\begin{array}{c}\text { Além do principio do poluidor-pagador da Lei } 12305 / 2010, \text { também foram } \\
\text { aplicadas as sançóes previstas pela Lei no } 9.605 / 1998, \text { que “dispốe sobre as } \\
\text { sançôes penais e administrativas derivadas de condutas e atividades lesivas ao } \\
\text { meio ambiente, e dá outras providências". }\end{array}$
\end{tabular}

III - a visão sistêmica, na gestão dos resíduos sólidos, que considere as variáveis ambiental, social, cultural, econômica, tecnológica e de saúde pública;

A gestão dos resíduos sólidos no Ecoponto do Itaigara se encontra interrelacionada com as variáveis descritas neste princípio.

IV - o desenvolvimento sustentável;

O desenvolvimento sustentável prevê três pilares: Econômico (o material recolhido vai para reutilização ou reciclagem); Social (o material conscientiza usuários e promove emprego para cooperativas); e, Ambiental (livrando as vias publicas do despejo inadequado dos RSU).

\begin{tabular}{|c|c|}
\hline $\begin{array}{l}\text { V - a ecoeficiência, mediante a compatibilização entre o } \\
\text { fornecimento, a preços competitivos, de bens e serviços } \\
\text { qualificados que satisfaçam as necessidades humanas e tragam } \\
\text { qualidade de vida e a redução do impacto ambiental e do } \\
\text { consumo de recursos naturais; }\end{array}$ & $\begin{array}{l}\text { A ecoeficiência, no caso descrito, se encontra relacionada com a segregação } \\
\text { e destinação dos materiais entregues pela população, para servirem como } \\
\text { insumos para a produção de novos produtos, reduzindo impactos ambientais } \\
\text { e consumo de recursos naturais. }\end{array}$ \\
\hline $\begin{array}{l}\text { VI - a cooperação entre as diferentes esferas do poder público, } \\
\text { o setor empresarial e demais segmentos da sociedade; }\end{array}$ & $\begin{array}{l}\text { Por meio do TAC descrito é possível verificar a cooperação entre diferentes } \\
\text { esferas: entes governamentais, empresas e a sociedade. }\end{array}$ \\
\hline $\begin{array}{l}\text { VII - a responsabilidade compartilhada pelo ciclo de vida dos } \\
\text { produtos; }\end{array}$ & $\begin{array}{l}\text { Os agentes envolvidos contribuem para minimizar o volume do RSU e } \\
\text { incentivam um conjunto de atribuiçóes individualizadas e encadeadas de } \\
\text { fabricantes, comerciantes, consumidores e do titular dos serviços públicos de } \\
\text { limpeza urbana do município de Salvador. }\end{array}$ \\
\hline $\begin{array}{l}\text { VIII - o reconhecimento do resíduo sólido reutilizável e } \\
\text { reciclável como um bem econômico e de valor social, gerador } \\
\text { de trabalho e renda e promotor de cidadania; }\end{array}$ & $\begin{array}{c}\text { O material recolhido pelo Ecoponto é enviando às cooperativas de materiais } \\
\text { recicláveis ou usinas de inertes. }\end{array}$ \\
\hline IX - o respeito às diversidades locais e regionais; & $\begin{array}{l}\text { O MP/Ba observou a localização geográfica. O bairro em questão permite, } \\
\text { pela maior renda e educaçáo formal dos moradores, facilidade na entrega dos } \\
\text { recicláveis, promovendo visibilidade para o correto manejo do RSU. }\end{array}$ \\
\hline $\mathrm{X}$ - o direito da sociedade à informação e ao controle social; & $\begin{array}{l}\text { Através de boletins de informação no site do MP/BA e da impressão de } \\
\text { panfletos acordados no TAC. }\end{array}$ \\
\hline XI - a razoabilidade e a proporcionalidade. & $\begin{array}{l}\text { Ao contrario da aplicação de sanções com alta penalização, o MP considerou } \\
\text { a disponibilidade dos recursos que os agentes poluidores possuíam. As } \\
\text { sançôes aplicadas obedeceram à capacidade de pagamento destes agentes. }\end{array}$ \\
\hline
\end{tabular}

Fontes: Procedimento investigatório no 003.0.29710/2011 MP/Ba. Lei 12305/2010. Elaboração das autoras.

Os benefícios trazidos pela atuação do MP para o município de Salvador e outros municípios do estado da Bahia tem sido positivos. Porém, o papel do MP restringe-se a sanar ou equiparar o dano já causado anteriormente, ou a reparação da norma não observada.

É de fundamental importância que o gestor público estimule algumas ações, descritas a seguir: correta roteirização da coleta seletiva, construção e a instalação de equipamentos públicos para coleta seletiva, como Ecopontos e Usinas de triagem e reciclagem, que recebem os resíduos recicláveis e evita o despejo em aterros sanitários; educação ambiental constante e ativa, que rejeite conteúdo deficiente e de alcance e eficácia limitados; a remuneraçáo de catadores e catadoras de matérias recicláveis, os reconhecendo como parceiros no manejo dos serviços de limpeza urbana; a compra e a disponibilizaçáo de carros elétricos para coleta dos catadores; a substituição dos chassis únicos de coleta para chassis multi coleta, evitando a compactação de materiais considerados como recursos econômicos e de preservação ambiental; estímulo a população para participação e para controle social dos planos de gerenciamento municipais de resíduos sólidos e dos orçamentos públicos correspondentes, dentre outros. 
Um ponto de destaque quanto à roteirização da coleta seletiva é que esta deve ser planejada, já que fornece suporte à modalidade de coleta seletiva "porta a porta", que acontece por meio da separaçáo prévia dos resíduos recicláveis domicíliares. Segundo Battistella (2014) a roteirização da coleta em um programa de coleta seletiva é instrumento que apoia o planejamento do manejo dos RSU, mesmo que este planejamento municipal não seja eficaz, já que otimiza recursos materiais e humanos.

Com relação ao Ecoponto, poucas pessoas além das que vivem em suas imediaçóes têm conhecimento de sua localização e, até mesmo, que vem disponibilizando um equipamento público voltado para recolhimento desse tipo de material. Mesmo a placa que divulga e fornece informaçóes sobre os tipos de resíduos que podem ser dispostos no local, é de pequena dimensão e instalada em local de pouca visibilidade, acessível apenas aos transeuntes que passam caminhando pela via pública.

Para Marchi (2015), a PNRS por si só, não será capaz de modificar a precária gestão dos resíduos sólidos urbanos no Brasil. Para tanto é necessário outras ações conjuntas com o poder público, as organizaçôes e os cidadãos.

A gestão dos RSU não é tarefa fácil, sobretudo para os municípios de pequeno e médio portes, pois exige uma visão integrada dos diversos segmentos que a constituem para a obtenção de resultados positivos, bem como a sustentabilidade dos programas implantados.

Em 2012, o município de Salvador criou a Secretaria Cidade Sustentável - SECIS, que se apresenta como a primeira secretaria do Brasil com foco na sustentabilidade. Pela divulgação do seu site, tem como missão "Ser o principal instrumento de concepção, execução e promoção das políticas de desenvolvimento sustentável do município de Salvador, de forma cooperativa e dinâmica, rumo a um melhor padráo de qualidade de vida para os soteropolitanos". Reconhece que uma cidade com o porte de Salvador precisa atender a objetivos sociais, ambientais, políticos e culturais, bem como a objetivos econômicos e físicos de seus cidadãos. Caso os gestores desta secretaria consigam implementar as açôes prometidas, será possível a promoção de um caminho que aproxime suas propostas ao que se encontra disposto na Lei 12.305/2010.

\section{CONCLUSÕES}

Os municípios enfrentam grandes desafios para a aplicação efetiva das exigências feitas pela PNRS, o que náo os desobrigam a cumprir este instrumento legal. Foi possível observar que a atuaçáo do Ministério Público do Estado da Bahia vem sendo relevante para a efetivação do preconizado pela Lei. Sem a participação deste órgáo, descrita neste estudo, a cidade do Salvador poderia não estar contando com o único e adequado equipamento público para a coleta de recicláveis, como o Ecoponto do Itaigara.

Este artigo, de caráter exploratório, objetivou examinar algumas praticas do processo de manejo dos resíduos sólidos, tais como o descarte, a coleta seletiva e a destinação final, gerados por empresas e pelos cidadãos no município de Salvador, Bahia, e como essas praticas podem suscitar intervenções do Ministério Público.

A pesquisa revelou a participação positiva do $\mathrm{MP} / \mathrm{Ba}$ na fiscalização de açóes que trazem impactos ambientais e na intermediação para a cooperaçáo entre o poder público municipal e o setor empresarial, resultando na construção do Ecoponto.

O estudo sinalizou a importância desse tipo de equipamento para a coleta de materiais recicláveis, relacionando os princípios da lei 12305/2010 com o conteúdo das açóes presentes no TAC do Ecoponto do Itaigara, trazendo esta discussão para o universo das práticas possíveis de serem alcançadas no setor. Revelou a existência de uma Secretaria Cidade Sustentável - SECIS no município Salvador, que permite, caso suas açóes sejam efetivadas, se ter um vislumbre de melhoria no gerenciamento dos resíduos sólidos urbanos.

Finalmente, percebeu-se ainda frágil atuação do município na construção e na instalação de Ecopontos. $\mathrm{O}$ TAC aconteceu em 2011. Em 2017, os outros dois Ecopontos planejados não foram disponibilizados, sinalizando a carência do município em conseguir superar o que se considera grande desafio para os serviços relacionados à limpeza urbana e ao manejo de resíduos sólidos: segregação na fonte, coleta e destinação final apropriados.

\section{REFERÊNCIAS}

BAHIA, Ministério Público do Estado da Bahia; CEAMA; Câmara Temática de Saneamento Básico. Programa Resíduos: Do lixão a Gestão sustentável. Disponível em: file:///C:/Users/Cristina/Downloads/novo-manual-de-apoio-do-programa-res\%C3\%ADduos.-do-lix\%C3\%A3o-\%C3\%A0-gest\%C3\%A3o-sustent\%C3\%A1vel.pdf Acesso em: 12 mai. 2018. 
BRASIL. Lei n ${ }^{\circ}$ 12.305/2010. Política Nacional de Resíduos Sólidos. Disponível em: http://www.planalto.gov.br/ccivil_03/_ato2007-2010/2010/lei/l12305.htm Acesso em: 15 ago. 2018.

BATTISTELLA, N. (2014). Avaliaçáo de modelo computacional para planejamento e otimizaçáo de rotas de coleta para catadores de materiais recicláveis (Dissertação de mestrado). Programa de Pós-graduação em Engenharia Ambiental, Universidade Federal de Santa Catarina, Florianópolis.

BRASIL. Lei no 8.625/1993. Lei Orgânica Nacional do Ministério Público. Disponível em: http://www.planalto.gov. br/ccivil_03/leis/L8625.htm Acesso em: 20 ago. 2018

BRASIL. Ministério das Cidades. Sistema Nacional de Informações sobre Resíduos Sólidos - 2016. Ano Base 2015. Disponível em : http://www.snis.gov.br/diagnostico-residuos-solidos/diagnostico-rs-2015 Acesso em: 23 fev. 2018

CONKE, Leonardo Silveira; NASCIMENTO, Elimar Pinheiro do. A coleta seletiva nas pesquisas brasileiras: uma avaliação metodológica. urbe, Rev. Bras. Gest. Urbana, Curitiba, v. 10, n. 1, p. 199-212, Apr. 2018 . Available from $<$ http://www.scielo.br/scielo.php?script=sci_arttext\&pid=S2175-33692018000100199\&lng=en\&nrm=iso $>$. access on 30 Nov. 2018. http://dx.doi.org/10.1590/2175-3369.010.001.ao14.

FERNANDES, Valdir; MALHEIROS, Tadeu Fabrício; PHILlIPI JR., Arlindo; CIOCE SAMPAIO, Carlos Alberto. Metodologia de Avaliação Estratégica de Processo de Gestão Ambiental Municipal. Saúde Soc. São Paulo, v.21, supl.3, p.128-143, 2012.

FERREIRA Evaldo de M; CRUVINEL, Karla A da S; COSTA, Eliabe S da. Disposição final dos resíduos sólidos urbanos: diagnóstico da gestấo do município de Santo Antônio de Goiás. REMOA. v.14, n.3, mai-ago. 2014, p.3401-3411

GODOY, Arlida Schmidt. Introdução à pesquisa qualitativa e suas possibilidades. Rev. adm. empres., São Paulo, v. 35, n. 2, p. 57-63, abr. 1995. Disponível em http://www.scielo.br/scielo.php?script=sci_arttext\&pid=S0034-75901995000200008\&lng=pt\&nrm=iso Acesso em: 22 ago. 2018.

LIMA, Maria Raquel Passos. Paradoxos da formalização: a inclusão social dos catadores de recicláveis a partir do caso do encerramento do aterro de Jardim Gramacho (RJ). Horiz. antropol., Porto Alegre, v. 24, n. 50, p. 145-180, Apr. 2018. Available from <http://www.scielo.br/scielo.php?script=sci_arttext\&pid=S0104-71832018000100145\&lng=en \&nrm=iso>. access on 05 Dec. 2018. http://dx.doi.org/10.1590/s0104-71832018000100006.

KLEIN, Flávio Bordino; GONCALVES-DIAS, Sylmara Lopes Francelino; JAYO, Martin. Gestão de resíduos sólidos urbanos nos municípios da Bacia Hidrográfica do Alto Tietê: uma análise sobre o uso de TIC no acesso à informação governamental. urbe, Rev. Bras. Gest. Urbana, Curitiba, v. 10, n. 1, p. 140-153, Apr. 2018 . Available from <http:// www.scielo.br/scielo.php?script=sci_arttext\&pid=S2175-33692018000100140\&lng=en\&nrm=iso $>$. access on 01 Dec. 2018. http://dx.doi.org/10.1590/2175-3369.010.001.ao10.

MANNARINO, Camille Ferreira; FERREIRA, João Alberto; GANDOLLA, Mauro. Contribuiçóes para a evolução do gerenciamento de resíduos sólidos urbanos no Brasil com base na experiência Européia. Eng. Sanit. Ambient., Rio de Janeiro, v. 21, n. 2, p. 379-385, June 2016 . Available from <http://www.scielo.br/scielo.php?script=sci_ arttext\&pid $=S 1413-41522016000200379 \& \operatorname{lng}=$ en\&nrm=iso $>$. access on 04 Dec. 2018. Epub June 20, 2016. http://dx.doi.org/10.1590/s1413-41522016146475.

MARCHI, Cristina Maria Dacach Fernandez. Novas perspectivas na gestão do saneamento: apresentação de um modelo de destinação final de resíduos sólidos urbanos. urbe, Rev. Bras. Gest. Urbana, Curitiba, v. 7, n. 1, p. 91-105, Apr. 2015.

RIBEIRO, Luiz Carlos de Santana et al . Aspectos econômicos e ambientais da reciclagem: um estudo exploratório nas cooperativas de catadores de material reciclável do Estado do Rio de Janeiro. Nova econ., Belo Horizonte, v. 24, n. 1, p. 191-214, Apr. 2014. Available from <http://www.scielo.br/scielo.php?script=sci_arttext\&pid=S010363512014000100191\&lng=en\&nrm=iso $>$. access on 05 Dec. 2018. http://dx.doi.org/10.1590/103-6351/1390. 